American Journal of Applied Sciences 9 (2): 246-249, 2012

ISSN 1546-9239

(C) 2012 Science Publications

\title{
A Simplified Two-Dimentional Unit Cell Model for Analyzing the Transverse Shear Stiffness of Three-Dimentional Truss-Like Core Sandwich Beam
}

\author{
${ }^{1}$ Suphattharachai Chomphan and ${ }^{2}$ Manit Leekitwattana \\ ${ }^{1}$ Department of Electrical Engineering, \\ Faculty of Engineering at Si Racha, \\ ${ }^{2}$ International Maritime College, \\ Kasetsart University, 199 M.6, Tungsukhla, \\ Si Racha, Chonburi, 20230, Thailand
}

\begin{abstract}
Problem statement: In structural analysis using finite element software, a complex threedimensional model affects the speed of calculation time. A simplified two-dimensional model should be used for analyzing structural responses to reduce the calculation time. Approach: This study presents a study on the analysis of the transverse shear stiffness of three-dimensional trusslike core sandwich beam using a simplified two-dimensional unit cell model. Three kinds of core topologies: A truss core, an X-truss core and a bi-directional corrugated-strip core are chosen to be analyzed in this study. The presented simplified two-dimensional unit cell model is compared in transverse shear stiffness with the three-dimensional finite element unit cell model. Results: In this study, the results show that the simplified two-dimensional unit cell model can be used for analyzing the transverse shear stiffness of three-dimensional truss-like core sandwich beam with a good correlative with the three-dimensional finite element unit cell model. Conclusion: From the finding, the transverse shear stiffness of three-dimensional truss-like core sandwich beam can be obtained from the simplified two-dimensional unit cell model. This simplified two-dimensional model can be used to substitute the complex three-dimensional finite element model; consequently, the speed of calculation time is increased.
\end{abstract}

Key words: Finite element, sandwich beam, unit cell, two-dimensional unit, element model, shear stiffness, simplified two-dimensional, transverse shear, truss-like core

\section{INTRODUCTION}

In recent structural engineering analysis, a finite element method is a tool for analyzing transverse shear stiffness of beam structures. It is, however, an expensive time-consuming method if applying the finite element method to three-dimensional models.

The force and distortion relationship of unit cell approach is an analytical method for analyzing the transverse shear stiffness of sandwich beams. Libove et al. (1951) have used this method in analytical study of simple corrugated core sandwich beams. Lok and Cheng (2000) have used it for analyzing the transverse shear stiffness of simple truss core sandwich beams. Leekitwattana et al. (2011) have also used the unit cell approach for analyzing the transverse shear stiffness of complex truss-like core sandwich beams. It was found that the force and distortion relationship of unit cell approach is an accurate method if applied for the truss-like core sandwich beam (Libove et al., 1951; Lok and Cheng, 2000; Leekitwattana et al., 2011).

This study aims to present an application of the force and distortion relationship of simplified twodimensional unit cell approach in analysis the transverse shear stiffness of three-dimensional trusslike core sandwich beams, as shown in Fig. 1.

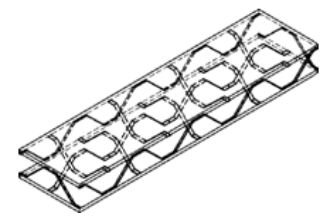

Fig.1: A three-dimensional truss-like core sandwich beam

Corresponding Author: Suphattharachai Chomphan, Department of Electrical Engineering, Faculty of Engineering at Si Racha, Kasetsart University, 199 M.6, Tungsukhla, Si Racha, Chonburi, 20230, Thailand 


\section{MATERIALS AND METHODS}

Fundamental of unit cell approach: The transverse shear stiffness of beams can be deduced from the relationship between the applied transverse shear force, $\mathrm{Q}_{\mathrm{y}}$ and the corresponded deflections $\delta_{\mathrm{y}}$ and $\delta_{\mathrm{z}}$ of a unit cell which is a repetitive unit of a sandwich beam (Leekitwattana et al., 2011), as demonstrated in Fig. 2.

The relationship between the applied transverse shear force, $\mathrm{Q}_{\mathrm{y}}$ and the corresponded deflections $\delta_{\mathrm{y}}$ and $\delta_{\mathrm{z}}$ can be expressed as Eq. 1. This expression provides the direct calculation of the transverse shear stiffness, $D_{\mathrm{Qy}}$.

$$
\mathrm{D}_{\mathrm{Qy}}=\frac{\mathrm{Q}_{\mathrm{y}}}{\frac{\delta_{\mathrm{y}}^{4}+\delta_{\mathrm{y}}^{8}}{\mathrm{~d}}+\frac{\delta_{\mathrm{z}}^{4}}{\mathrm{~s}_{\mathrm{c}}}}
$$

Three-dimensional finite element unit cell model: Three-dimensional finite element model of unit cell, as shown in Fig. 3, is analyzed. The model has a fixed support at line 1-1' and a roller support at line 5-5'. Additional constraint boundary conditions are set up along the lines 4-4' and $8-8$ ' to maintain the displacement equality of both lines in the z-direction.

The unit cell consists of the top and bottom steel faceplates and a truss-like core. These parts are modeled using the SOLID45 element type-an eightnode element having three degrees of freedom in nodal translations at each node-from the ANSYS element library Swanson Analysis Systems, 2007. In this study, the typical $2 \mathrm{~mm}$ finite element mesh size is used. The connections between the faceplates and core elements are defined as fully rigid.

The commercial finite element software ANSYS Release 11 is used in this study. The ANSYS is run under the operating software MS Windows XP Professional Version 2002. The hardware condition is a desktop computer with Intel® CoreTM 2 CPU 6600 @ $2.40 \mathrm{GHz}$ and $1.98 \mathrm{~GB}$ of RAM.

Simplified two-dimensional unit cell model: Instead of using the three-dimensional finite element model, the unit cell can be presented in a simplified twodimensional model (Leekitwattana et al., 2011). Leekitwattana et al. (2011) have presented the model and consequent solution matrices for obtaining the corresponded deflections $\delta_{\mathrm{y}}{ }^{4}, \delta_{\mathrm{y}}{ }^{8}$ and $\delta_{\mathrm{z}}{ }^{4}$ of the unit cell presented in Fig. 2.

In this study, the solution matrices are encoded in and solved by the commercial mathematical software MATLAB Version 6.1. The MATLAB is also run under the same operating software and hardware conditions as those used with the ANSYS.

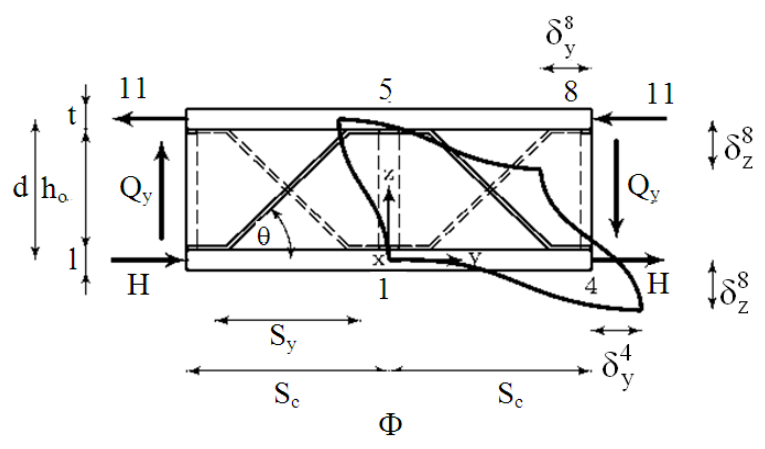

Fig. 2: A method for analyzing the transverse shear stiffness from the force and distortion relationship of unit cell (Leekitwattana et al., 2011)

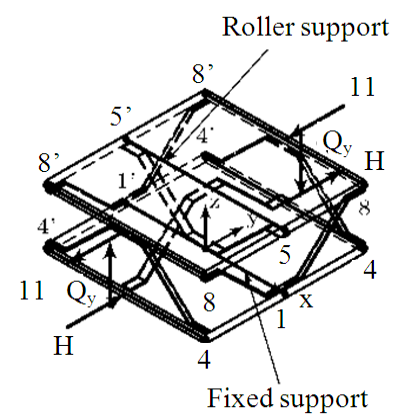

Fig. 3: A three-dimensional finite element model of unit cell
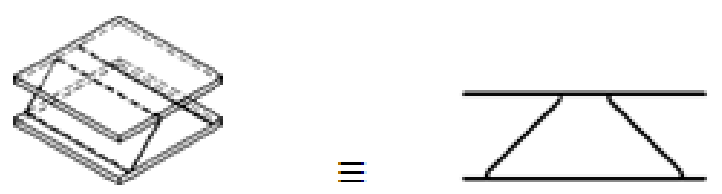

(a)
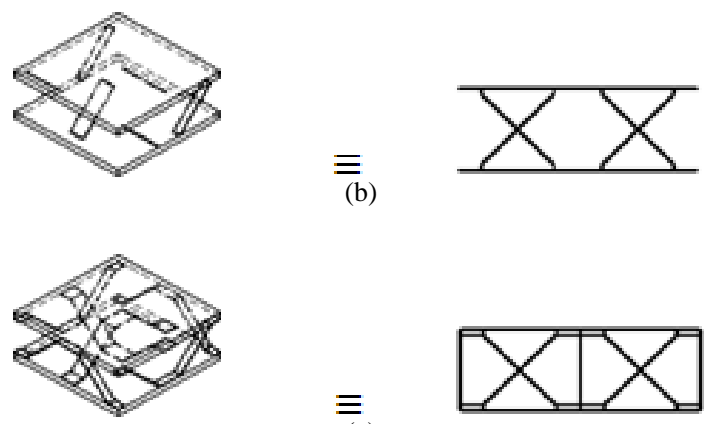

(b)

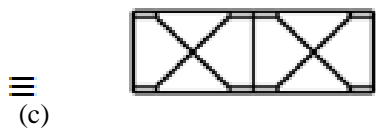

Fig. 4: A three-dimensional model and its equivalent two-dimensional model of (a) truss core, (b) Xtruss core and (c) bi-directional corrugated-strip core (Leekitwattana et al., 2011) 
Am. J. Applied Sci., 9 (2): 246-249, 2012

Table 1: Configuration of unit cells

\begin{tabular}{lll}
\hline & Value & \\
& Truss core & \\
Dimensions & 100 & \\
\hline Width of sandwich beam, $\mathrm{b}$ & 12 & \\
Thickness of sandwich faceplate, $\mathrm{t}$ & 120 & \\
Depth of sandwich core, $\mathrm{h}_{\mathrm{c}}$ & 100 & \\
Width of core plate, $\mathrm{b}_{\mathrm{c}}$ & 2 & \\
Thickness of core plate, $\mathrm{t}_{\mathrm{c}}$ & 20 & \\
Length of flat leg of core plate, $\mathrm{f}_{\mathrm{c}}$ & & \\
\hline & & $\mathrm{Unit}$ \\
Table 2: Physical properties of steel & Value & $\mathrm{N} / \mathrm{mm}^{2}$ \\
Properties & 355 & $\mathrm{~N} / \mathrm{mm}^{2}$ \\
\hline Yield stress, $\mathrm{f}_{\mathrm{y}}$ & 206,000 & \\
Modulus of elasticity, $\mathrm{E}_{\mathrm{s}}$ & 0.30 & \\
Poisson's ratio, $\mathrm{V}_{\mathrm{s}}$ &
\end{tabular}

Studied core topologies: In this study, threedimensional truss-like cores: A truss core, an X-truss core and a bi-directional corrugated-strip core, as shown in Fig. 4, are studied using the three-dimensional finite element unit cell approach. The geometrical dimensions of these core are presented in Table 1. These core topologies are also studied using the simplified twodimensional unit cell approach.

Material properties of steel: In this study, the steel with perfectly elastic-plastic property is used. The tension and compression behaviors of steel are assumed the same. The physical properties of steel are defined in Table 2. In the ANSYS, this material property of steel is defined using the bi-linear model.

\section{RESULTS}

Based on the transverse shear stiffness formulation techniques presented in the materials and methods section, the transverse shear stiffness, $\mathrm{D}_{\mathrm{Qy}}$, of the sandwich beam with three core topologies, i.e., the truss core, the X-truss core and the bi-directional corrugatedstrip core, are obtained and presented in Fig. 5.

In Fig. 5, the transverse shear stiffness, $D_{\mathrm{Qy}}$, is first factorized by $E_{s} t$ where $E_{s}$ is the modulus of elasticity of steel and $t$ is the thickness of sandwich faceplate. Then, it is plotted against $\mathrm{s}_{\mathrm{y}} / \mathrm{d}$ in the range of $0.25 \leq \mathrm{s}_{\mathrm{y}} / \mathrm{d} \leq 2.0$ where $\mathrm{s}_{\mathrm{y}}$ is the horizontal projection of the extended local neutral axis of the inclined part of the core and $d$ is the effective depth of the sandwich beam, i.e., $d=t+h_{c}$. Here, $s_{y} / d$ is used to define the angle of the inclined part of the core. It is equal to $\left(\mathrm{s}_{\mathrm{c}^{-}}\right.$ $\left.2 \mathrm{f}_{\mathrm{c}}\right) /\left(\mathrm{h}_{\mathrm{c}}-\mathrm{t}_{\mathrm{c}}\right)$. Thus, the horizontal length of the unit cell, sc, can be obtained from this expression (Chomphan and Leekitwattana, 2011).

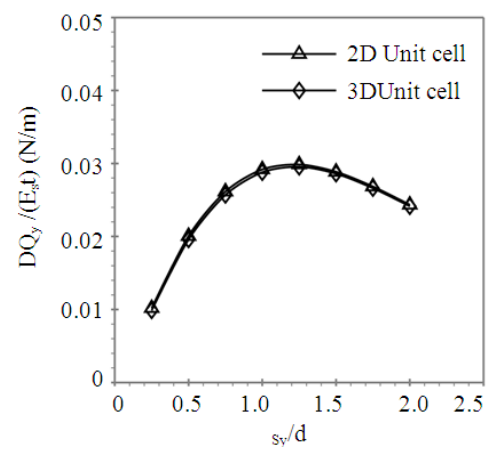

(a)

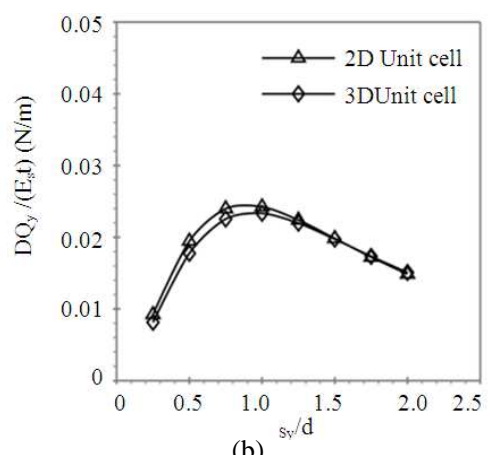

(b)

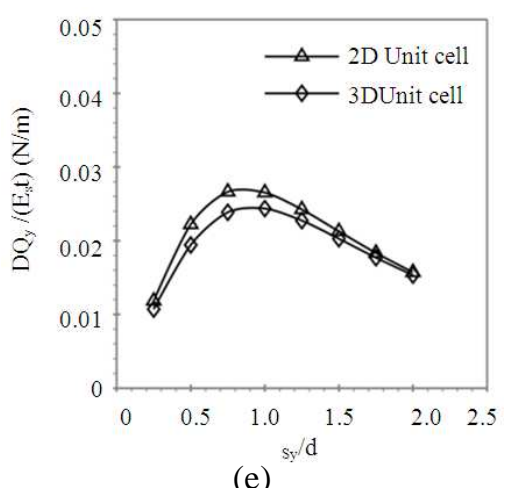

(e)

Fig. 5: Factorized transverse shear stiffness, $D_{Q y} / E_{s} t$, of (a) truss core, (b) X-truss core and (c) bidirectional corrugated-strip core sandwich beams obtained at any ${ }_{\text {sy }} \mathrm{d}$ ratio from the threedimensional unit cell approach and from the simplified two-dimensional unit cell approach 


\section{DISCUSSION}

From the comparison of the factorized transverse shear stiffness, $D_{Q y} / E_{s} t$, of the truss core sandwich beams obtained from the three-dimensional unit cell approach using finite element method and the simplified two-dimensional unit cell approach as presented in Fig. 5a, it can be seen that both approaches agree very well with each other.

From the comparison of the factorized transverse shear stiffness, $\mathrm{D}_{\mathrm{Qy}} / \mathrm{E}_{\mathrm{s}} \mathrm{t}$, of the X-truss core sandwich beams obtained from both approaches as presented in Fig. 5b, it can also be seen that the simplified twodimensional unit cell approach agrees well with the three-dimensional unit cell approach with a few percentage differences. The percentage difference of $6.4 \%$, for example, occurs at $\mathrm{s}_{\mathrm{y}} / \mathrm{d}=0.75$.

It can be seen from Fig. 5c that the simplified twodimensional unit cell approach applied for the bidirectional corrugated-strip core sandwich beams also agrees well with the three-dimensional unit cell approach. The percentage differences between these approaches are less than $15 \%$. The maximum percentage difference of $14.4 \%$ occurs at sy/d $=0.50$. The percentage difference of $11.6 \%$ occurs at sy/d $=0.75$ and the percentage difference of $2.5 \%$ occurs at sy/d $=2.0$.

According to these comparisons, it can be seen that the transverse shear stiffness, $\mathrm{D}_{\mathrm{Qy}}$, of the threedimensional truss-like core sandwich beams obtained from the simplified two-dimensional unit cell approach is well consistent with the three-dimensional unit cell approached applied with the finite element method. Therefore, the simplified two-dimensional unit cell approach can be used for analyzing the transverse shear stiffness, $\mathrm{D}_{\mathrm{Qy}}$, of not only the simple truss core sandwich beams but also the complex truss-like core sandwich beams, i.e., the $\mathrm{X}$-truss core and the bidirectional corrugated-strip core sandwich beams presented in this study.

The simplified two-dimensional unit cell approach is considerably more advantageous than the threedimensional unit cell approach applied with the finite element method. This is because the simplified twodimensional unit cell approach can be modeled in simple line-art model. There is no requirement to do three-dimensional solid model in this approach.

\section{CONCLUSION}

This study presents the application of the simplified two-dimensional unit cell approach to obtain the transverse shear stiffness, $D_{\mathrm{Qy}}$, of the threedimensional truss-like core sandwich beams. Three core topologies of the truss core, the X-truss core and the bidirectional corrugated-strip core are presented as examples of three-dimensional truss-like core topology. The responses of the transverse shear stiffness, $\mathrm{D}_{\mathrm{Qy}}$, obtained from the simplified two-dimensional unit cell approach applied with the MATLAB are presented and compared with those obtained from the threedimensional unit cell approach applied with the ANSYS. It is found that the simplified two-dimensional unit cell approach agrees very well with the threedimensional unit cell approach. The simplified twodimensional unit cell approach can be applied to the three-dimensional truss-like core sandwich beams as an alternative to the finite element method; consequently, it can be used to increase the speed of calculation time.

\section{REFERENCES}

Chomphan, S. and M. Leekitwattana, 2011. A reduced finite element model for analyzing the transverse shear stiffness of truss-like core sandwich beam. J. Comput. Sci., 7: 1474-1477. DOI: 10.3844/jcssp.2011.1474.1477

Leekitwattana, M., S.W. Boyd and R.A. Shenoi, 2011. Evaluation of the transverse shear stiffness of a steel bi-directional corrugated-strip-core sandwich beam. J. Constructional Steel Res., 67: 248-254. DOI: 10.1016/j.jcsr.2010.07.010

Libove, C., R.E. Hubka and R.K. Hubka,, 1951. Elastic Constants for Corrugated-Core Sandwich Plates. 1st Edn., NACA, Washington, D.C., pp: 105.

Lok, T.S. and Q.H. Cheng, 2000. Elastic stiffness properties and behavior of truss-core sandwich panel. J. Struct. Eng., 126: 552-559. DOI: 10.1061/(ASCE)0733-9445(2000)126:5(552) 